\title{
Perpaduan Algoritma Kriptografi Atbash dan Autokey Cipher dalam Mengamankan Data
}

\author{
Muhammad Fadlan ${ }^{1, *}$, Rosmini $^{1}$, Haryansyah $^{2}$ \\ ${ }^{1}$ Program Studi Sistem Informasi, STMIK PPKIA Tarakanita Rahmawati, Tarakan, Indonesia \\ ${ }^{2}$ Program Studi Teknik Informatika, STMIK PPKIA Tarakanita Rahmawati, Tarakan, Indonesia \\ Email: ${ }^{1, *}$ fadlan@ppkia.ac.id, ${ }^{2}$ rosmini@ ppkia.ac.id, ${ }^{3}$ haryansyah@ppkia.ac.id \\ Email Penulis Korespondensi: fadlan@ppkia.ac.id
}

\begin{abstract}
Abstrak-Keamanan data merupakan hal penting yang wajib dilakukan di era siber. Penggunaan berbagai macam teknologi digital dalam membantu berbagai kegiatan manusia perlu diimbangi dengan keamanan data yang memadai. Salah satu cara yang dapat digunakan dalam mengamankan data adalah melalui kriptografi. Atbash cipher merupakan salah satu teknik kriptografi yang digunakan dalam mengamankan data. Namun, algoritma ini memiliki kelemahan karena hanya memanfaatan proses membalikkan posisi karakter yang akan diamankan. Oleh karena itu, penelitian ini mengusulkan sebuah model kriptografi yang dapat memaksimalkan keamanan data dari atbash cipher. Model yang diusulkan adalah melalui perpaduan antara atbash cipher dengan autokey cipher. Ujicoba yang dilakukan terhadap model yang diusulkan memiliki tingkat kesuksesan sebesar $100 \%$, artinya bahwa pesan tersandi hasil proses enkripsi yang diusulkan sukses dikembalikan kebentuk semula melalui proses dekripsi yang diusulkan. Hasil dari penelitian ini juga menunjukkan bahwa algoritma kriptografi atbash cipher yang dipadukan dengan algoritma autokey cipher, mampu menghasilkan pesan tersandi yang sulit untuk dipecahkan.
\end{abstract}

Kata Kunci: Atbash; Autokey; Data; Kriptografi; Keamanan

Abstract-Data security is an important thing that must be done in the cyber era. The use of various kinds of digital technology in helping various human activities needs to be balanced with adequate data security. One of the ways that can be used in securing data is through cryptography. Atbash cipher is one of the cryptographic techniques used in securing data. However, this algorithm has a weakness because it only uses the process of reversing the position of the characters to be secured. This study proposes a cryptographic model that can maximize data security from the atbash cipher. The proposed model is a combination of the atbash cipher with the autokey cipher. The tests carried out on the proposed model have a $100 \%$ success rate, meaning that the encrypted message resulting from the proposed encryption process has been successfully restored to its original form through the proposed decryption process. The results of this study indicate that the atbash cipher cryptographic algorithm, combined with the autokey cipher algorithm can produce an encrypted message that is more difficult to crack.

Keywords: Atbash; Autokey; Data; Cryptography; Security

\section{PENDAHULUAN}

Data memiliki peranan yang sangat penting bagi kelangsungan sebuah institusi maupun perusahaan di era Cyber Security maupun Revolusi Industri 4.0. Terdapat tiga unsur penting dalam sebuah data, yaitu Confidentiality, Integrity, dan Availability [1], [2]. Mudahnya proses pendistribusian data melalui berbagai macam platform teknologi mampu membawa risiko yang besar terhadap data yaitu masalah keamanan data [3], [4]. Menjaga keutuhan maupun keamanan data merupakan salah satu tantangan terberat di era digital [4]. Jatuhnya data maupun informasi penting milik sebuah institusi kepada orang lain tentu membawa kerugian dalam keberlangsungan sebuah institusi. Oleh karena itu, diperlukan sebuah teknik untuk menjaga keamanan data. Salah satu teknik yang banyak digunakan saat ini adalah Kriptografi.

Kriptografi merupakan ilmu yang dapat dimanfaatkan dalam mengamankan data [5], [6]. Kriptografi memegang peranan penting dalam memberikan keamanan terhadap data yang dikirimkan melalui internet, hal ini membuat data tidak mudah dikenali oleh pihak eksternal yang tidak berkepentingan. Ilmu ini dapat digunakan pada hampir semua saluran komunikasi baik dalam jaringan maupun tanpa jaringan [7] [8]. Terdapat dua jenis teknik utama yang populer digunakan dalam berbagai jenis algoritma kriptografi yaitu, teknik substitusi dan teknik transposisi. Algoritma kriptografi yang menjadi fokus dalam penelitian ini adalah Atbash Cipher dan Autokey Cipher. Atbash dan Autokey Cipher merupakan algoritma kriptografi yang termasuk kedalam algoritma kriptografi substitusi [8].

Atbash Cipher merupakan jenis kriptografi yang termasuk kedalam teknik substitusi. Algoritma ini dapat digunakan untuk mengamankan data yang bersifat rahasia [9], [10]. Cara kerja algoritma ini adalah setiap huruf dari abjad akan dibalik posisinya. Sabagai contoh, karakter A digantikan dengan karakter Z, B digantikan dengan $\mathrm{Y}$ dan seterusnya. Namun, perubahan posisi tersebut akan sangat bergantung pada jumlah karakter dan urutan karakter tersebut dari keseluruhan jumlah karakter yang digunakan. Kelemahan utama algoritma kriptografi yang menerapkan teknik substitusi adalah tingkat keamanan yang cenderung belum maksimal, termasuk Atbash Cipher. Permasalahan utama yang akan diteliti dalam penelitian ini adalah terkait dengan kelemahan tingkat keamanan data pada algoritma kriptografi Atbash Cipher. Kelemahan Atbash Cipher lainnya adalah termasuk salah satu algoritma kriptografi yang klasik dan hanya memanfaatan proses membalikkan posisi karakter yang akan diamankan, hal ini cenderung dapat dengan mudah diretas dan keamanan data menjadi kurang maksimal [11], [12]. 
Salah satu solusi yang dapat digunakan dalam memaksimalkan tingkat keamanan suatu algoritma kriptografi adalah melalui perpaduan dengan algoritma kriptografi lainnya [12]-[14]. Autokey Cipher merupakan pengembangan dari algoritma caesar dan viginere cipher [15]. Cara untuk melakukan proses pengamanan data sama seperti cipher dan viginere cipher, yang membedakannya adalah pengaturan kunci yang digunakan dalam proses enkripsi dan dekripsi [16].

Beberapa penelitian relevan telah dilakukan sebelumnya, salah satunya adalah penelitian yang bertujuan untuk melakukan pengamanan data melalui kombinasi dua metode antara atbash dan viginere cipher [9]. Penelitian lain telah melakukan kombinasi atbash cipher dan bitplane complexity segmentation dalam melakukan penyembunyian pesan didalam media citra [12]. Penelitian berikutnya telah melakukan peningkatan keamanan algoritma viginere cipher menggunakan chaos function [16]. Penelitian menggunakan autokey cipher yang dimodifikasi juga telah dilakukan dalam mengamankan data melalui perpaduan dengan caesar cipher [8].

Oleh karena itu, penelitian ini bertujuan untuk melakukan pengembangan model kriptografi substitusi Atbash Cipher, sehingga dihasilkan tingkat keamanan data yang lebih baik. Solusi yang diusulkan dalam penelitian adalah melalui proses perpaduan antara algoritma Atbash Cipher dan Autokey Cipher. Dalam penelitian ini, media yang akan digunakan sebagai uji coba terhadap konsep yang diusulkan adalah berupa teks yang terdiri dari sekumpulan karakter huruf maupun angka.

\section{METODOLOGI PENELITIAN}

Tahapan penelitian yang dilakukan dalam penelitian ini secara garis besar dapat dilihat pada Gambar 1. Pada Gambar 1, terlihat bahwa tahapan awal dari penelitian ini adalah melakukan studi atau kajian awal terkait dengan permasalahan dalam penelitian ini.

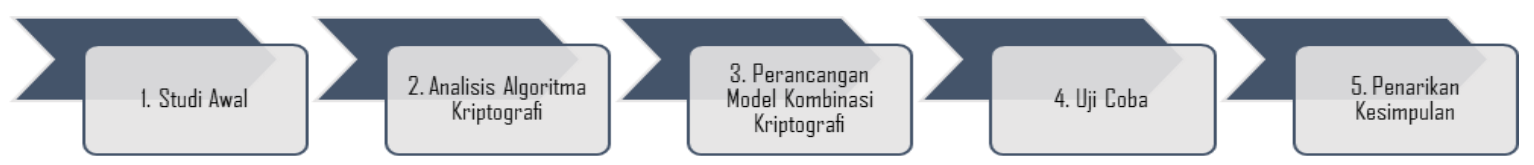

Gambar 1. Tahapan Penelitian

Langkah kedua adalah melakukan analisis algoritma kriptografi yang akan digunakan dalam penelitian ini, yakni Atbash dan Autokey Cipher. Langkah ketiga dilakukan perancangan model kombinasi dari algoritma atbash dan autokey cipher. Model tersebut dapat dilihat pada Gambar 2 dan Gambar 3. Langkah keempat dilakukan ujicoba terhadap model yang telah dirancang. Langkah terakhir adalah melakukan penarikan kesimpulan terhadap penelitian yang telah dilakukan.

\subsection{Usulan Model Enkripsi}

Dalam penelitian ini, proses enkripsi yang diusulkan secara garis besar dapat dilihat pada Gambar 2. Proses Enkripsi dilakukan melalui dua tahapan utama yaitu menggunakan algoritma atbash dan autokey cipher.

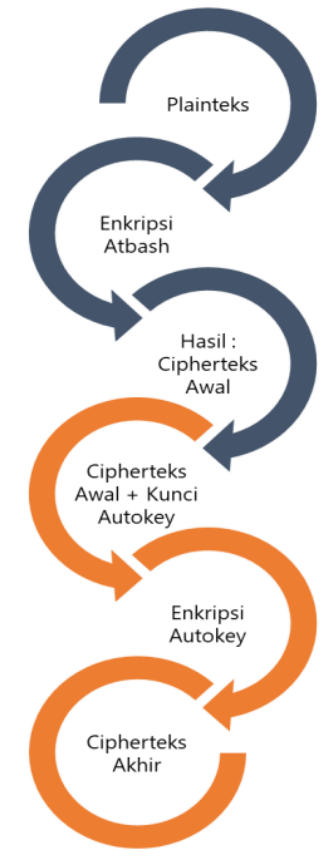

Gambar 2. Usulan proses enkripsi 
Pada Gambar 2, terlihat bahwa proses enkripsi yang diusulkan dalam penelitian ini dibagi kedalam 6 tahapan, antara lain:

a. Tahap pertama, menyediakan plainteks dan penentuan jumlah keseluruhan karakter yang digunakan

b. Tahap kedua, melakukan proses enkripsi dengan algoritma atbash. Proses enkripsi dilakukan dengan mengacu pada Persamaan 1 [9]-[12].

$C(i)=(n-1)-P(i)$

Dengan ketentuan, $C(i)$ merupakan hasil proses enkripsi atau cipherteks, $P(i)$ merupakan indeks karakter yang akan dienkripsi, " $n$ ” merupakan jumlah alfabet yang digunakan. Dalam penelitian ini, dibatasi hanya terdapat 62 karakter yang digunakan yaitu karakter huruf besar (A-Z), huruf kecil (a-z) dan angka (0-9). Dalam algoritma ini, huruf awal dari karakter yang terdapat dalam deretan karakter. yang digunakan akan diubah menjadi karakter terakhir dari jumlah karakter yang digunakan. Deretan karakter yang digunakan dapat dilihat pada tabel 1.

Tabel 1. Sampel Karakter

\begin{tabular}{cc}
\hline Indeks & Karakter \\
\hline 0 & $\mathrm{~A}$ \\
1 & $\mathrm{~B}$ \\
2 & $\mathrm{C}$ \\
3 & $\mathrm{D}$ \\
4 & $\mathrm{E}$ \\
5 & $\mathrm{~F}$ \\
$\ldots$ & $\ldots$ \\
26 & 0 \\
27 & 1 \\
28 & 2 \\
29 & 3 \\
$\ldots$ & $\ldots$ \\
36 & $\mathrm{a}$ \\
37 & $\mathrm{~b}$ \\
38 & $\mathrm{c}$ \\
$\ldots$ & $\ldots$ \\
59 & $\mathrm{x}$ \\
60 & $\mathrm{y}$ \\
61 & $\mathrm{z}$ \\
\hline
\end{tabular}

Pada tabel 1, terlihat bahwa susunan karakter yang digunakan dimulai dari karakter huruf besar (A-Z), Angka (0-9), diikuti dengan huruf kecil (a-z).

c. Tahap ketiga merupakan hasil dari proses enkripsi tahap pertama

d. Tahap keempat, menyediakan kunci yang akan digunakan dalam algoritma autokey dan plainteks yang merupakan hasil enkripsi tahap pertama

e. Tahap kelima, melakukan proses enkripsi algoritma autokey cipher. Proses enkripsi dilakukan dengan mengacu pada Persamaan 2 [15]-[17].

$C(i)=(p(i)+k(i)) \bmod m$

Dengan ketentuan, $c(i)$ merupakan proses enkripsi, $p(i)$ merupakan indeks dari karakter yang akan di enkripsi, $k(i)$ merupakan indeks dari kunci dan " $m$ " merupakan jumlah keseluruhan karakter yang digunakan. Persamaan 2 merupakan persamaan yang biasa digunakan dalam algoritma viginere cipher. Autokey cipher merupakan pengembangan dari algoritma viginere cipher, khususnya dari sisi kunci yang digunakan. Dalam algoritma autokey, jika kunci memiliki panjang yang kurang dari plainteks maka kunci tersebut akan digabungkan dengan plainteks itu sendiri.

f. Tahap keenam merupakan hasil akhir dari proses enkripsi yang diusulkan

\subsection{Usulan Proses Dekripsi}

Dalam penelitian ini, proses dekripsi yang diusulkan secara garis besar dapat dilihat pada Gambar 3. Pada gambar

3 , terlihat bahwa proses dekripsi yang diusulkan dalam penelitian ini dibagi kedalam 6 tahapan, antara lain:

a. Tahap pertama, menyediakan cipherteks, penentuan jumlah karakter dan kunci yang akan digunakan dalam algoritma autokey

b. Tahap kedua, melakukan proses dekripsi dengan algoritma autokey. Proses dekripsi dilakukan dengan mengacu pada Persamaan 3 yang merupakan kebalikan dari proses yang terdapat pada Persamaan 2.

$p(i)=(C(i)-k(i)) \bmod m$ 
c. Tahap ketiga merupakan hasil dari proses dekripsi tahap pertama, sekaligus menjadi plainteks awal yang akan didekripsi kembali dengan algoritma atbash

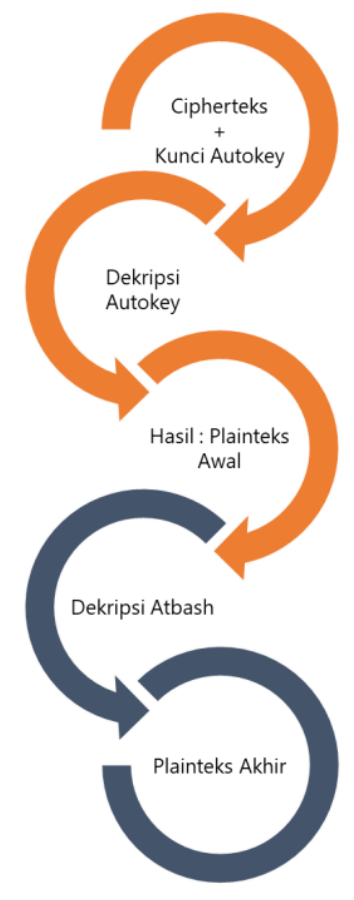

Gambar 3. Usulan Proses Dekripsi

d. Tahap keempat, melakukan proses dekripsi algoritma atbash. Proses dekripsi dilakukan dengan mengacu pada Persamaan 4 yang merupakan proses kebalikan dari yang terdapat pada Persamaan 1.

$p(i)=(m-1)-C(i) \bmod m$

e. Tahap kelima merupakan hasil akhir dari proses dekripsi yang diusulkan.

\section{HASIL DAN PEMBAHASAN}

Dalam bagian ini, dilakukan ujicoba terhadap usulan proses enkrip dan dekripsi dengan menggunakan perpaduan algoritma atbash dan autokey cipher seperti yang terdapat pada gambar 2 dan gambar 3.

\subsection{Proses Enkripsi}

Proses enkripsi akan dilakukan berdasarkan model yang telah diusulkan seperti pada gambar 2. Plainteks yang akan digunakan adalah “Jurnal MIB Juli 2021". Plainteks tersebut telah mewakili karakter yang terdapat pada tabel 1, yakni terdapat karakter huruf besar, huruf kecil dan angka.

Langkah berikutnya adalah melakukan proses enkripsi tahap pertama dengan menggunakan atbash cipher seperti yang terdapat pada Persamaan 1. Sebagai contoh karakter "J" memiliki indeks karakter 9 dengan keluruhan karakter yang digunakan adalah 62 karakter, sehingga dengan menggunakan Persamaan 1,

$$
C(i)=(n-1)-P(i)=(62-1)-9=61-9=52=q
$$

Didapatkan hasil akhir sebesar 52, yang kemudian jika dikonversi kembali menjadi karakter “ $q$ ”. Proses perhitungan seperti ini akan dilakukan untuk semua karakter plainteks sebelum dilakukan proses enkripsi di tahapan berikutnya. Secara keseluruhan hasil enkripsi tahap pertama dapat dilihat pada kolom Enkripsi Pertama di Tabel 2.

Setelah hasil enkripsi tahap pertama didapatkan, dilakukan proses enkripsi tahap kedua dengan menggunakan autokey cipher. Kunci yang digunakan dalam ujicoba ini adalah "budidarma”. Proses enkripsi dilakukan berdasarkan Persamaan 2. Sebagai contoh karakter "J" setelah di enkripsi menggunakan atbash menghasilkan karakter "q", karakter inilah yang kemudian akan di enkripsi menggunakan autokey cipher. Dalam algoritma autokey, setiap karakter plainteks memiliki pasangan kunci masing-masing. Berikut contoh proses enkripsi menggunakan autokey cipher, jika diketahui plainteks adalah karakter "q" dengan indeks 52, kunci yang digunakan adalah karakter " $b$ " (karakter awal dari kunci "budidarma") yang memiliki indeks 37 dan jumlah karakter sebanyak 62. 


$$
C(i)=(p(i)+k(i)) \bmod m=(52+37) \bmod 62=89 \bmod 62=27=1
$$

Berdasarkan proses enkripsi tahap kedua didapatkan hasil sebesar 27, yang jika dikonversi berdasarkan tabel 1 maka menghasilkan karakter "1". Sehingga, proses enkripsi karakter plainteks "J" setelah melewati dua tahapan proses enkripsi menghasilkan karakter "1". Hasil proses enkripsi tahap kedua tersebut dapat dilihat pada tabel 2.

Tabel 2. Hasil Proses Enkripsi

\begin{tabular}{|c|c|c|c|}
\hline Plainteks & $\begin{array}{c}\text { Enkripsi Tahap } \\
\text { Pertama }\end{array}$ & Kunci & $\begin{array}{c}\text { Enkripsi Tahap } \\
\text { Kedua }\end{array}$ \\
\hline $\mathrm{J}$ & $52=q$ & $\mathrm{~b}$ & 1 \\
\hline $\mathrm{u}$ & $5=F$ & $\mathrm{u}$ & $\mathrm{Z}$ \\
\hline $\mathrm{r}$ & $8=\mathrm{I}$ & d & 1 \\
\hline $\mathrm{n}$ & $12=\mathrm{M}$ & $\mathrm{i}$ & $\mathrm{u}$ \\
\hline $\mathrm{a}$ & $25=Z$ & d & $\mathrm{C}$ \\
\hline 1 & $14=0$ & $\mathrm{a}$ & o \\
\hline \multicolumn{4}{|c|}{ spasi } \\
\hline M & $49=n$ & $\mathrm{r}$ & $\mathrm{e}$ \\
\hline I & $53=r$ & $\mathrm{~m}$ & $\mathrm{~d}$ \\
\hline B & $60=y$ & $\mathrm{a}$ & $\mathrm{g}$ \\
\hline \multicolumn{4}{|c|}{ spasi } \\
\hline $\mathrm{J}$ & $52=q$ & $\mathrm{~J}$ & $\mathrm{z}$ \\
\hline $\mathrm{u}$ & $5=F$ & $\mathrm{u}$ & $\mathrm{z}$ \\
\hline 1 & $14=O$ & $\mathrm{r}$ & $\mathrm{F}$ \\
\hline $\mathrm{i}$ & $17=\mathrm{R}$ & $\mathrm{n}$ & $\mathrm{E}$ \\
\hline \multicolumn{4}{|c|}{ spasi } \\
\hline 2 & $33=7$ & $\mathrm{a}$ & $\mathrm{H}$ \\
\hline 0 & $35=9$ & 1 & $\mathrm{U}$ \\
\hline 2 & $33=7$ & M & $\mathrm{j}$ \\
\hline 1 & $34=8$ & $\mathrm{I}$ & $\mathrm{G}$ \\
\hline
\end{tabular}

Dalam tabel 2 terlihat bahwa kunci yang digunakan adalah "budidarma”, dikarenakan jumlah karakter kunci tersebut lebih pendek dibandingkan dengan karakter plainteks maka dilakukan penambahan karakter kunci tersebut dengan mengambil karakter plainteks mulai urutan paling awal. Sehingga, karakter kunci akan memiliki jumlah yang sama banyaknya dengan karakter plainteks. Pengaturan seperti ini merupakan salah satu ciri khas dari algoritma autokey cipher. Dengan menggunakan proses enkripsi yang diusulkan pada penelitian ini, seperti yang dapat dilihat pada Tabel 2, plainteks "Jurnal MIB Juli 2021" setelah melalui proses enkripsi dihasilkan karakter cipherteks "1zluCo edg zzFE HUjg”.

\subsection{Proses Dekripsi}

Untuk membuktikan kebenaran dari proses enkripsi yang diusulkan, maka perlu dilakukan proses dekripsi terhadap cipherteks yang dihasilkan dari proses enkripsi. Proses dekripsi akan dilakukan berdasarkan model yang telah diusulkan seperti pada gambar 3. Cipherteks yang akan digunakan adalah "1zluCo edg zzFE HUjg” dengan kunci autokey yang sama seperti saat melakukan proses enkripsi yaitu "budidarma".

Langkah berikutnya adalah melakukan proses dekripsi tahap pertama dengan mengacu pada Persamaan 3. Proses dekripsi tahap pertama tersebut memiliki proses yang hampir sama seperti proses enkripsi tahap kedua. Sebagai contoh karakter cipherteks pertama yang akan dienkripsi adalah karakter "8" yang memiliki indeks berdasarkan Tabel 1, sebesar 27. Kunci yang digunakan adalah karakter " $b$ " (karakter awal dari kunci "budidarma") yang memiliki indeks 37 dan jumlah karakter sebanyak 62. Sehingga,

$$
p(i)=(C(i)-k(i)) \bmod m=(27-37) \bmod 62=-10 \bmod 62=\mathbf{5 2}=\mathbf{q}
$$

Berdasarkan proses dekripsi tahap pertama tersebut didapatkan hasil sebesar 52, yang jika dikonversi berdasarkan Tabel 1 maka menghasilkan karakter plainteks awal "q". Selanjutnya, dilakukan proses dekripsi tahap kedua dengan menggunakan atbash cipher terhadap karakter plainteks yang didapatkan dari proses dekripsi sebelumnya. Proses dekripsi tahap kedua dilakukan dengan mengacu pada Persamaan 4. Sebagai contoh karakter yang akan didekripsi adalah karakter "q" dengan nilai indeks 52, kunci "b" dengan indeks 37 dan jumlah karakter sebanyak 62. Sehingga,

$$
p(i)=(m-1)-C(i) \bmod m=(62-1)-52 \bmod 62=61-52=\mathbf{9}=\mathbf{J}
$$

Berdasarkan proses dekripsi tahap kedua terhadap karakter "q" didapatkan hasil akhir yaitu 9 dengan nilai konversi adalah karakter huruf "J". Proses dekripsi tahap kedua ini dilakukan secara berulang terhadap semua 
ISSN 2614-5278 (media cetak), ISSN 2548-8368 (media online)

Available Online at https://ejurnal.stmik-budidarma.ac.id/index.php/mib DOI 10.30865/mib.v5i3.3019

karakter hasil dari proses dekripsi tahap pertama. Secara keseluruhan hasil dari model proses dekripsi yang diusulkan dalam penelitian ini dapat dilihat pada Tabel 3.

Tabel 3. Hasil Proses Dekripsi

\begin{tabular}{cccc}
\hline Cipherteks & Kunci & $\begin{array}{c}\text { Dekripsi Tahap } \\
\text { Pertama }\end{array}$ & $\begin{array}{c}\text { Dekripsi } \\
\text { Tahap Kedua }\end{array}$ \\
\hline 1 & $\mathrm{~b}$ & $52=\mathrm{q}$ & $\mathrm{J}$ \\
$\mathrm{z}$ & $\mathrm{u}$ & $5=\mathrm{F}$ & $\mathrm{u}$ \\
$\mathrm{l}$ & $\mathrm{d}$ & $8=\mathrm{I}$ & $\mathrm{r}$ \\
$\mathrm{u}$ & $\mathrm{i}$ & $12=\mathrm{M}$ & $\mathrm{n}$ \\
$\mathrm{C}$ & $\mathrm{d}$ & $25=\mathrm{Z}$ & $\mathrm{a}$ \\
$\mathrm{o}$ & $\mathrm{a}$ & $14=\mathrm{O}$ & $\mathrm{l}$ \\
& & spasi & \\
$\mathrm{e}$ & $\mathrm{r}$ & $49=\mathrm{n}$ & $\mathrm{M}$ \\
$\mathrm{d}$ & $\mathrm{m}$ & $53=\mathrm{r}$ & $\mathrm{I}$ \\
$\mathrm{g}$ & $\mathrm{a}$ & $60=\mathrm{y}$ & $\mathrm{B}$ \\
& & spasi & \\
$\mathrm{z}$ & $\mathrm{J}$ & $52=\mathrm{q}$ & $\mathrm{J}$ \\
$\mathrm{z}$ & $\mathrm{u}$ & $5=\mathrm{F}$ & $\mathrm{u}$ \\
$\mathrm{F}$ & $\mathrm{r}$ & $14=\mathrm{O}$ & 1 \\
$\mathrm{E}$ & $\mathrm{n}$ & $17=\mathrm{R}$ & $\mathrm{i}$ \\
& & spasi & \\
$\mathrm{H}$ & $\mathrm{a}$ & $33=7$ & 2 \\
$\mathrm{U}$ & $\mathrm{l}$ & $35=9$ & 0 \\
$\mathrm{j}$ & $\mathrm{M}$ & $33=7$ & 2 \\
$\mathrm{G}$ & $\mathrm{I}$ & $34=8$ & 1 \\
\hline
\end{tabular}

Pada tabel 3, dapat dilihat bahwa proses dekripsi tahap pertama terhadap cipherteks " $1 z l u C o$ edg $z z F E$ HUjg” adalah "qFIMZO nry qFOR 7978”. Karakter ini kemudian didekripsi lagi untuk kedua kalinya sehingga menghasilkan karakter “Jurnal MIB Juli 2021”. Hal ini membuktikan bahwa proses dekripsi menggunakan model yang diusulkan mampu menghasilkan karakter yang sama seperti karakter plainteks awal sebelum dienkripsi.

\subsection{Hasil Pengujian}

Model pengamanan data yang diusulkan melalui perpaduan dua algoritma kriptorafi berhasil diujicoba dalam melakukan proses enkripsi maupun dekripsi terhadap data teks. Model pengamanan data ini terdiri atas dua bagian penting dalam kriptografi yakni enkripsi dan dekripsi. Seperti yang dapat dilihat pada tabel 2, proses enkripsi terhadap plainteks "Jurnal MIB Juli 2021" menghasilkan karakter cipherteks pertama " $q F I M N O$ nry qFOR 7978 ”. Karakter cipherteks tersebut kemudian dienkripsi lagi untuk kedua kalinya menggunakan autokey cipher menjadi "1zluCo edg zzFE HUjg”.

Terlihat bahwa hasil enkripsi dengan menggunakan perpaduan dua algoritma mampu menghasilkan karakter cipherteks yang berbeda dari atbash cipher saja, sehingga mampu meningkatkan keamanan dari penggunaan algoritma atbash cipher tersebut. Hal ini terjadi karena adanya dua tahapan proses enkripsi yang harus dilakukan sehingga membuat pihak-pihak tertentu yang ingin mengetahui data sebenarnya menjadi lebih sulit. Proses dekripsi terhadap karakter cipherteks sukses dilakukan dengan melalui dua tahapan proses dekripsi. Tahap pertama melalui dekripsi autokey cipher dan tahap kedua melalui atbash cipher. Seperti yang dapat dilihat pada tabel 3, hasil dekripsi mampu menghasilkan karakter plainteks seperti semula. Beberapa hasil uji coba lainnya terhadap penerapan model pengamanan data yang diusulkan dapat dilihat pada Tabel 4.

Tabel 4. Hasil Uji Coba

\begin{tabular}{cccccc}
\hline No & Plainteks & Kunci Autokey & Hasil Enkripsi & Hasil Dekripsi & Status \\
\hline 1. & Kunci & ab1 & Zgd7b & Kunci & Sukses \\
2. & Rahasia & stmik & aSEHr8z & Rahasia & Sukses \\
3. & Password & 12345 & Lrab80iO & Password & Sukses \\
\hline
\end{tabular}

Dalam tabel 4, terlihat bahwa proses enkripsi dilakukan terhadap beberapa kata dengan menggunakan kunci yang berbeda pula. Hasilnya menunjukkan semua plainteks setelah dienkripsi berhasil dikembalikan menjadi bentuk semula melalui proses dekripsi yang diusulkan. Hal ini menunjukkan bahwa model yang diusulkan berhasil melalukan proses enkripsi maupun proses dekripsi. 


\section{KESIMPULAN}

Berdasarkan penelitian yang telah dilakukan, disimpulkan bahwa tingkat keamanan sebuah algoritma kriptografi substitusi klasik dapat dimaksimalkan melalui perpaduan dengan algoritma kriptografi lainnya. Dalam penelitian ini algoritma kriptografi atbash cipher dipadukan dengan algoritma autokey cipher, mampu menghasilkan pesan tersandi yang sulit untuk dipecahkan. Hal ini dikarenakan proses enkripsi dilakukan melalui dua tahapan yakni melalui algoritma atbash dan autokey cipher. Penelitian lebih lanjut dapat dilakukan dengan mengembangkan model kriptografi dalam penelitian ini dan dapat mengimplementasi model kriptografi perpaduan algoritma atbash dan autokey ini diberbagai bidang dalam mengamankan data yang bersifat penting maupun rahasia.

\section{UCAPAN TERIMAKASIH}

Terima kasih kepada Kementerian Riset dan Teknologi / Badan Riset dan Inovasi Nasional yang telah membiayai penelitian ini melalui skema hibah kompetitif nasional Penelitian Dosen Pemula (PDP) Tahun 2021.

\section{REFERENCES}

[1] S. Aldossary and W. Allen, "Data Security, Privacy, Availability and Integrity in Cloud Computing: Issues and Current Solutions," Int. J. Adv. Comput. Sci. Appl., vol. 7, no. 4, pp. 485-498, 2016, doi: 10.14569/ijacsa.2016.070464.

[2] A. Tchernykh, U. Schwiegelsohn, E. ghazali Talbi, and M. Babenko, "Towards understanding uncertainty in cloud computing with risks of confidentiality, integrity, and availability," J. Comput. Sci., vol. 36, 2019, doi: 10.1016/j.jocs.2016.11.011.

[3] H. N. Noor Muchsin, D. E. Sari, D. R. Ignatius Moses Setiadi, and E. H. Rachmawanto, "Text Encryption using Extended Bit Circular Shift Cipher," in Proceedings of 2019 4th International Conference on Informatics and Computing, ICIC 2019, 2019, pp. 0-4, doi: 10.1109/ICIC47613.2019.8985708.

[4] J. R. Paragas, A. M. Sison, and R. P. Medina, "An Improved Hill Cipher Algorithm using CBC and Hexadecimal SBox," in 2019 IEEE Eurasia Conference on IOT, Communication and Engineering, ECICE 2019, 2019, pp. 77-81, doi: 10.1109/ECICE47484.2019.8942717.

[5] F. Maqsood, M. Ahmed, M. Mumtaz, and M. Ali, "Cryptography: A Comparative Analysis for Modern Techniques," Int. J. Adv. Comput. Sci. Appl., vol. 8, no. 6, 2017, doi: 10.14569/ijacsa.2017.080659.

[6] N. Atikah, M. R. Ashila, D. R. I. M. S. Setiadi, E. H. Rachmawanto, and C. A. Sari, "AES-RC4 Encryption Technique to Improve File Security," in Proceedings of 2019 4th International Conference on Informatics and Computing, ICIC 2019, 2019.

[7] O. G. Abood and S. K. Guirguis, “A Survey on Cryptography Algorithms,” Int. J. Sci. Res. Publ., vol. 8, no. 7, 2018, doi: 10.29322/ijsrp.8.7.2018.p7978.

[8] M. D. Sinaga, N. S. B. Sembiring, F. Tambunan, and C. J. M. Sianturi, "Hybrid Cryptography WAKE (Word Auto Key Encryption) and Binary Caesar Cipher Method for Data Security," 2018 6th Int. Conf. Cyber IT Serv. Manag. CITSM 2018, no. Citsm, pp. 1-5, 2019, doi: 10.1109/CITSM.2018.8674346.

[9] M. I. Afandi and N. Nurhayati, "Implementasi Algoritma Vigenere Cipher Dan Atbash Cipher Untuk Keamanan Teks Pada Aplikasi Catatan Berbasis Android," IT J., vol. 8, no. 1, pp. 30-41, 2020.

[10] N. Sureshkumar, A. K. Nanda, P. Kollapudi, and B. Harish, "Provision of Security Using Substitution Ciphers," J. Crit. Rev., vol. 7, no. 04, pp. 918-923, 2020.

[11] I. S. Sabana and L. Tanti, "Pengembangan Model Keamanan Data Inventory Dengan," J. FTIK, vol. 1, no. 1, pp. 607$618,2020$.

[12] S. A. Meliala, "Perancangan Aplikasi Pengkodean dan Penyembunyian Pesan dalam Media Citra dengan Menggunakan Algoritma Atbash Chiper dan Metode Bit Plane Complexity Segmentation," J. Pelita Inform., vol. 18, no. 1, pp. 113$120,2019$.

[13] D. P. Timothy and A. K. Santra, "A hybrid cryptography algorithm for cloud computing security," 2017 Int. Conf. Microelectron. Devices, Circuits Syst. ICMDCS 2017, vol. 2017-Janua, pp. 1-5, 2017, doi: 10.1109/ICMDCS.2017.8211728.

[14] I. Gunawan, "Kombinasi Algoritma Caesar Cipher dan Algoritma RSA untuk pengamanan File Dokumen dan Pesan Teks," InfoTekJar (Jurnal Nas. Inform. dan Teknol. Jaringan), vol. 2, no. 2, pp. 124-129, 2018, doi: 10.30743/infotekjar.v2i2.266.

[15] O. Grošek, E. Antal, and T. Fabšič, "Remarks on breaking the Vigenère autokey cipher," Cryptologia, vol. 43, no. 6, pp. 486-496, 2019, doi: 10.1080/01611194.2019.1596997.

[16] B. Triandi, E. Ekadiansyah, R. Puspasari, L. T. Iwan, and F. Rahmad, "Improve Security Algorithm Cryptography Vigenere Cipher Using Chaos Functions,” 2018 6th Int. Conf. Cyber IT Serv. Manag. CITSM 2018, no. Citsm, pp. 1-5, 2019, doi: 10.1109/CITSM.2018.8674376.

[17] S. D. Nasution, G. L. Ginting, M. Syahrizal, and R. Rahim, "Data Security Using Vigenere Cipher and Goldbach Codes Algorithm," Int. J. Eng. Res. Technol., vol. 6, no. 01, pp. 360-363, 2017. 